\title{
Morphometric and volumetric comparison of 102 children with symptomatic and asymptomatic Chiari malformation Type I
}

\author{
*Siri Sahib S. Khalsa, MD, ${ }^{1}$ Ndi Geh, MD, ${ }^{1}$ Bryn A. Martin, PhD,, ${ }^{2,3}$ Philip A. Allen, PhD, ${ }^{2}$ \\ Jennifer Strahle, MD, ${ }^{4}$ Francis Loth, PhD, ${ }^{2}$ Desale Habtzghi, PhD, ${ }^{2}$ Aintzane Urbizu Serrano, PhD, ${ }^{2}$ \\ Daniel McQuaide, ${ }^{2}$ Hugh J. L. Garton, MD, MHSc, ${ }^{1}$ Karin M. Muraszko, MD, ${ }^{1}$ and \\ Cormac O. Maher, MD1
}

${ }^{1}$ Department of Neurosurgery, University of Michigan, Ann Arbor, Michigan; ${ }^{2}$ Conquer Chiari Research Center, University of Akron, Ohio; ${ }^{3}$ Neurophysiological Imaging and Modeling Laboratory, University of Idaho, Moscow, Idaho; and ${ }^{4}$ Department of Neurological Surgery, Washington University in St. Louis, Missouri

\begin{abstract}
OBJECTIVE Chiari malformation Type I (CM-I) is typically defined on imaging by a cerebellar tonsil position $\geq 5 \mathrm{~mm}$ below the foramen magnum. Low cerebellar tonsil position is a frequent incidental finding on brain or cervical spine imaging, even in asymptomatic individuals. Nonspecific symptoms (e.g., headache and neck pain) are common in those with low tonsil position as well as in those with normal tonsil position, leading to uncertainty regarding appropriate management for many patients with low tonsil position and nonspecific symptoms. Because cerebellar tonsil position is not strictly correlated with the presence of typical CM-I symptoms, the authors sought to determine if other 2D morphometric or 3D volumetric measurements on MRI could distinguish between patients with asymptomatic and symptomatic CM-I.
\end{abstract}

METHODS The authors retrospectively analyzed records of 102 pediatric patients whose records were in the University of Michigan clinical CM-I database. All patients in this database had cerebellar tonsil position $\geq 5 \mathrm{~mm}$ below the foramen magnum. Fifty-one symptomatic and 51 asymptomatic patients were matched for age at diagnosis, sex, tonsil position, and tonsil morphology. National Institutes of Health ImageJ software was used to obtain six 2D anatomical MRI measurements, and a semiautomated segmentation tool was used to obtain four 3D volumetric measurements of the posterior fossa and CSF subvolumes on MRI.

RESULTS No significant differences were observed between patients with symptomatic and asymptomatic CM-I related to tentorium length ( 50.3 vs $51.0 \mathrm{~mm} ; p=0.537$ ), supraoccipital length ( $39.4 \mathrm{vs} 42.6 \mathrm{~mm} ; p=0.055$ ), clivus-tentorium distance (52.0 vs $52.1 \mathrm{~mm} ; p=0.964$ ), clivus-torcula distance ( 81.5 vs $83.3 \mathrm{~mm} ; p=0.257$ ), total posterior fossa volume (PFV; 183.4 vs $190.6 \mathrm{ml} ; p=0.250)$, caudal PFV (152.5 vs $159.8 \mathrm{ml} ; p=0.256$ ), fourth ventricle volume to caudal PFV ratio $(0.0140$ vs $0.0136 ; p=0.649)$, or CSF volume to caudal PFV ratio $(0.071$ vs $0.061 ; p=0.138)$.

CONCLUSIONS No clinically useful 2D or 3D measurements were identified that could reliably distinguish pediatric patients with symptoms attributable to CM-I from those with asymptomatic CM-I.

https://thejns.org/doi/abs/10.3171/2017.8.PEDS17345

KEY WORDS Chiari malformation Type I; morphometrics; syringomyelia; volumetrics

$\mathrm{C}$ HIARI malformation Type I (CM-I) is typically defined on imaging by cerebellar tonsil position $\geq 5$ $\mathrm{mm}$ below the foramen magnum. ${ }^{1,6}$ Although the use of this measurement alone to establish the diagnosis of CM-I on imaging is widespread, there are clear limita- tions to this diagnostic criterion. Although low tonsil position may certainly influence the development of CM-I symptoms, tonsil position as an isolated variable is a poor predictor of the presence and/or severity of such symptoms. ${ }^{12,15,16,20,24,28,37,41,44}$ Some individuals with tonsil posi-

ABBREVIATIONS CM-I = Chiari malformation Type I; PFV = posterior fossa volume.

SUBMITTED June 29, 2017. ACCEPTED August 8, 2017.

INCLUDE WHEN CITING Published online November 10, 2017; DOI: 10.3171/2017.8.PEDS17345.

* Drs. Khalsa and Geh contributed equally to this work. 
tion $<5 \mathrm{~mm}$ below the foramen magnum may present with typical CM-I symptoms or syringomyelia. $.17,34$ Conversely, many asymptomatic or minimally symptomatic individuals have low tonsil position. 7,24,28,29,35,37,43

Because the number of cranial and cervical imaging studies have been increasing for decades, the incidental discovery of individuals with low tonsil position has become more common. ${ }^{14,24,25,42}$ Using the tonsil position criterion, current estimates of CM-I prevalence among patients undergoing MRI range from $0.8 \%$ to $3.7 \%$ in children ${ }^{2,24,35,37}$ and from $0.24 \%$ to $0.9 \%$ in adults. $25,35,42$ Symptomatic CM-I seems to be much less prevalent. ${ }^{2}$ This suggests that additional diagnostic imaging criteria beyond the standard measurement of tonsil position would be useful for determining the best candidates for surgical treatment.

We compared various morphometric parameters of the posterior cranial fossa between symptomatic and asymptomatic children, all of whom fulfilled diagnostic criteria for CM-I by tonsil position. The purpose of this comparison was to identify other measures on imaging that might differentiate patients who are symptomatic. The morphometric parameters used in our comparison of symptomatic versus asymptomatic CM-I included 3D volumetric analyses of the posterior fossa and CSF spaces, in addition to a number of 2D morphometric measurements.

In a preliminary, hypothesis-generating study of a smaller database, we assessed the capabilities of 19 different anatomical measurements of posterior fossa anatomy. We selected the most promising of these measures for assessment in this larger study and added a semiautomated technique for assessing posterior fossa volumes (PFVs). Because our primary goal was to identify any radiographic measures that might readily differentiate between patients with symptomatic versus asymptomatic CM-I, we assessed their behavior in 2 cohorts of clearly symptomatic and clearly asymptomatic patients, as assessed clinically. Although this limited the ability of the study to determine the usefulness of these parameters in a sample of less clear-cut patients, any value not found to discriminate in such a diagnostically clear setting would be very unlikely to perform well in a broader context.

Methodologically, a case-control format was selected. Symptomatic and asymptomatic pediatric patients were matched for age and sex to account for these variables that are known to independently influence cranial morphology, as well as for tonsil position and morphology, because these are already accepted (albeit imperfect) predictors of CM-I symptomatology.

\section{Methods \\ Patient Selection}

After approval by the University of Michigan institutional review board, patients were selected for this study via retrospective chart and MR image review of the University of Michigan clinical database. All patients in this data set were younger than 18 years at the time of initial diagnosis and had cerebellar tonsil position $\geq 5 \mathrm{~mm}$ below the foramen magnum. For this study, we identified patients in the data set who we considered either definitely asymptomatic (no neurological symptoms attributable to CM-
I) or definitely symptomatic (classic CM-I symptoms). Symptoms considered attributable to CM-I were Valsalvainduced occipital headaches and neck pain, central sleep apnea, extremity numbness or paresthesias, dysphagia, poor fine motor skills, and unsteady gait. Patients with nonspecific symptoms or unclear symptomatic status were not included.

We identified 51 patients with symptomatic CM-I and matched this group to 51 patients with asymptomatic CM-I according to age at diagnosis, sex, tonsil position (within a 2-mm difference), and tonsil morphology (rounded vs pointed). All patients considered to be symptomatic had Chiari decompression surgery. None of the asymptomatic patients had Chiari decompression surgery. For surgically treated patients, all measurements were made from the initial preoperative MR image. Because the objective of this study was to identify morphometric and volumetric differences between symptomatic and asymptomatic patients, we did not match for any features other than those mentioned above.

\section{D and 3D Morphometric Measurements}

In this study, we examined 2D morphometric measurements (tonsil position, basilar impression, tentorium length, supraoccipital length, clivus-tentorium distance, and clivus-torcula distance $)^{40}$ in addition to $3 \mathrm{D}$ volumetric measurements (total PFV, caudal PFV, and total CSF/cisternal space to PFV ratio). All measurements were made by a single observer (N.G.) who was blinded to the symptomatic or asymptomatic status of the patient at the time of measurement.

The presence or absence of a syrinx was noted for each patient, although not used to define the groups. Syrinx was defined as a central spinal fluid collection with a diameter $>3 \mathrm{~mm}$, whereas a diameter $\leq 3 \mathrm{~mm}$ was considered a dilated central canal. This definition was used to avoid the inclusion of thin spinal fluid collections that are less likely to be clinically significant or causally associated with CM-I. ${ }^{36}$

For the 2D measurements, sagittal T1-weighted MR images were manually reviewed to obtain six $2 \mathrm{D}$ measurements (Fig. 1). The following measurements were obtained based on a single manually selected slice, without multiplanar reconstruction: tonsil position with respect to the foramen magnum (for use in the matching process), tentorium length, supraoccipital length, clivus-tentorium distance, and clivus-torcula distance. These 2D morphometric measurements were made using National Institutes of Health ImageJ software. ${ }^{30}$

The 3D volumetric measurements were made on axial T2-weighted MR images using a custom semiautomated volume and CSF segmentation tool described previously. ${ }^{19}$ Voxel size for these scans ranged from 0.2 to $1.3 \mathrm{~mm}$ in plane resolution and 4.0- to 7.7- $\mathrm{mm}$ slice thickness. Volumes were calculated by determining the number of voxels within the posterior cranial fossa via Canny edge detection, then multiplying the number of voxels by the 3 dimensions of pixel spacing embedded within the MRI DICOM file. The CSF volume was determined by isolating connected voxels with a minimum intensity corresponding to CSF on T2-weighted imaging. 


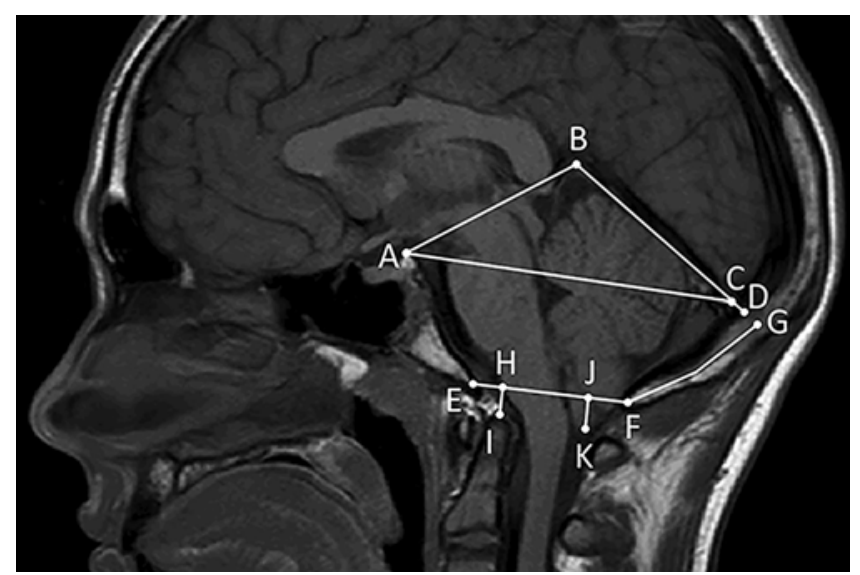

FIG. 1. Sagittal MR image indicating morphometric landmarks and lines. Clivus-tentorium distance $(A B)$, tentorium length $(B D)$, clivus-torcula line $(A C)$, McRae's line (EF), supraoccipital length (FG), basilar impression (HI), and tonsil position (JK).

The total PFV was defined as the volume posterior to a plane passing through the tips of the clivus and tentorium (line $\mathrm{AB}$ of Fig. 1), inferior to the tentorium, anterior to the occipital bone, and superior to the foramen magnum. The caudal PFV was the portion of the PFV inferior to a plane extending between the tip of the clivus and torcula (line AC of Fig. 1). The CSF/caudal PFV ratios (Fig. 2) were assessed as a measure of posterior fossa crowding. A smaller CSF/caudal PFV ratio indicates a more significant degree of crowding within the posterior fossa due to displacement of CSF.

All 102 patients with CM-I (51 asymptomatic and 51 symptomatic) underwent measurement and comparison of basilar impression, tentorium length, supraoccipital length, and clivus-tentorium distance. Seventy-eight patients underwent volumetric analysis for total PFV (12 pairs were excluded from volumetric analysis due to poor axial image quality preventing edge detection, lack of axial T2weighted images, and incomplete sets of axial images that excluded the foramen magnum). Seventy-four patients underwent subvolume analysis for CSF volume, clivustorcula distance, and caudal PFV (2 additional pairs were excluded due to the presence of a large arachnoid cyst that was expected to confound CSF volume analysis and an anomalous gantry that interfered with clivus-torcula distance measurement). Hypothesis testing was completed using the paired t-test. A p value $<0.05$ was considered statistically significant.

\section{Results}

By design, the symptomatic and asymptomatic groups were closely matched for age, sex, tonsil position, and morphology (Table 1). The mean $( \pm \mathrm{SD}$ ) ages for the symptomatic group $(8.0 \pm 5.3$ years $)$ and the asymptomatic group $(7.9 \pm 5.3$ years $)$ were similar $(\mathrm{p}=0.23)$. The mean $( \pm \mathrm{SD})$ tonsil position was $11.4 \pm 4.7 \mathrm{~mm}$ below the foramen magnum in symptomatic patients and $10.9 \pm 4.1 \mathrm{~mm}$ in individuals without symptoms $(\mathrm{p}=0.11)$. There were 25 boys and 26 girls in each group. Among the 51 symptomatic patients, 21 had a syrinx, 21 had a dilated central canal, and 9 had no syrinx. Among the 51 asymptomatic patients, 6 had a syrinx, 24 had a dilated central canal, and 21 had no syrinx.

Results of the comparison of 2D morphometric and 3D volumetric measurements are shown in Table 1. Independent groups t-tests were used to compare group means. After matching for age at diagnosis, tonsil position within a 2-mm difference, tonsil morphology (rounded vs pointed), and sex, no significant differences were observed between patients with symptomatic and asymptomatic CM-I with respect to tentorium length $(50.3$ vs $51.0 \mathrm{~mm}$; $\mathrm{p}=$ 0.537 ), supraoccipital length (39.4 vs $42.6 \mathrm{~mm} ; \mathrm{p}=0.055$ ), clivus-tentorium distance (52.0 vs $52.1 \mathrm{~mm}$; $\mathrm{p}=0.964)$, clivus-torcula distance ( 81.5 vs $83.3 \mathrm{~mm}$; $\mathrm{p}=0.257)$, total PFV (183.4 vs $190.6 \mathrm{ml} ; \mathrm{p}=0.250)$, caudal PFV (152.5 vs $159.8 \mathrm{ml} ; \mathrm{p}=0.256$ ), fourth ventricle volume to caudal PFV ratio (0.0140 vs $0.0136 ; p=0.649)$, and CSF volume to caudal PFV ratio ( 0.071 vs $0.061 ; p=0.138)$. There was a 1.1-mm mean difference between groups in basilar impression, which did achieve statistical significance (5.9 vs

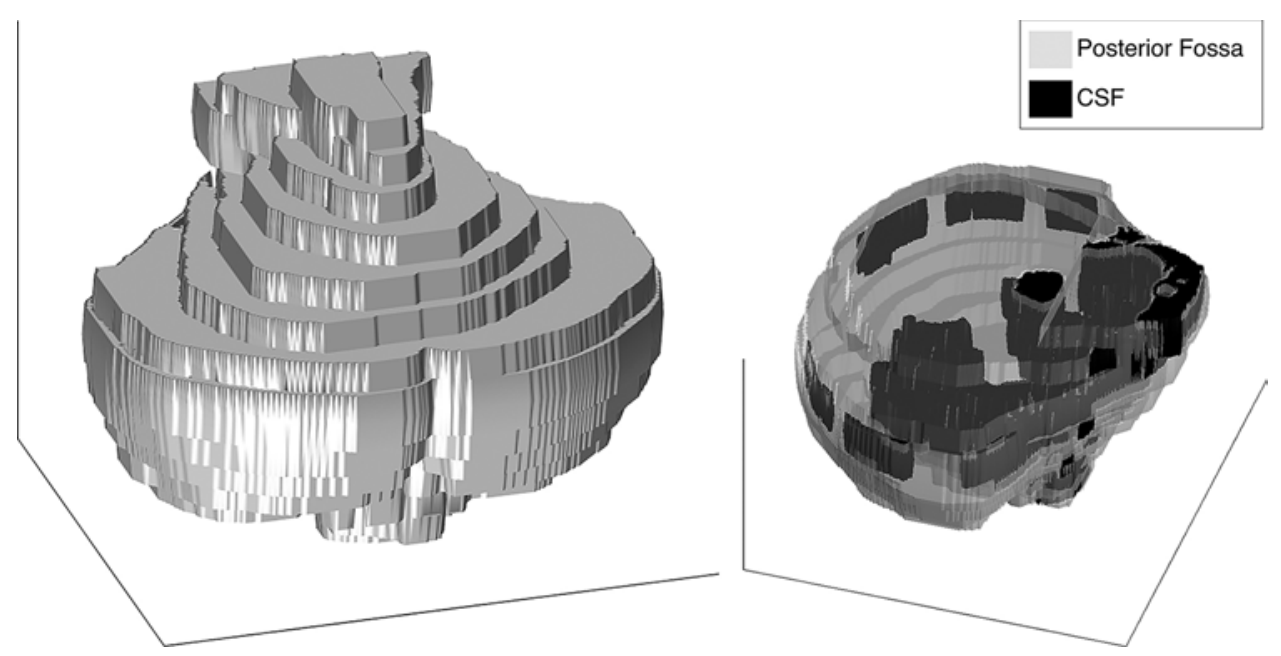

FIG. 2. 3D illustration. Left: Total PFV. Right: Caudal PFV (gray) and CSF volume (black). 
TABLE 1. Comparison of morphometric data between matched symptomatic and asymptomatic patients with CM-I

\begin{tabular}{|c|c|c|c|c|c|}
\hline Variable & No. of Patients & Mean (SD) & Mean Paired Difference (SD) & $95 \% \mathrm{Cl}$ & p Value (2-tailed) \\
\hline Age at diagnosis, yrs & & & $0.08(0.50)$ & -0.06 to 0.23 & 0.225 \\
\hline Symptomatic & 51 & $8.0(5.3)$ & & & \\
\hline Asymptomatic & 51 & $7.9(5.3)$ & & & \\
\hline Tonsil position, $\mathrm{mm}$ & & & $0.58(2.51)$ & -0.13 to 1.29 & 0.105 \\
\hline Symptomatic & 51 & $11.4(4.7)$ & & & \\
\hline Asymptomatic & 51 & $10.9(4.1)$ & & & \\
\hline Basilar impression, mm & & & $1.09(3.40)$ & 0.14 to 2.05 & 0.026 \\
\hline Symptomatic & 51 & $-5.9(3.0)$ & & & \\
\hline Asymptomatic & 51 & $-7.0(3.1)$ & & & \\
\hline Tentorium length, $\mathrm{mm}$ & & & $-0.71(8.14)$ & -3 to 1.58 & 0.537 \\
\hline Symptomatic & 51 & $50.3(5.8)$ & & & \\
\hline Asymptomatic & 51 & $51.0(6.6)$ & & & \\
\hline Supraoccipital length, $\mathrm{mm}$ & & & $-3.2(11.7)$ & -6.53 to 0.07 & 0.055 \\
\hline Symptomatic & 51 & $39.4(7.4)$ & & & \\
\hline Asymptomatic & 51 & $42.6(7.0)$ & & & \\
\hline Clivus-tentorium distance, $\mathrm{mm}$ & & & $-0.07(8.90)$ & -2.95 to 2.82 & 0.964 \\
\hline Symptomatic & 51 & $52.0(6.1)$ & & & \\
\hline Asymptomatic & 51 & $52.1(7.9)$ & & & \\
\hline Clivus-torcula distance, $\mathrm{mm}$ & & & $-1.8(9.3)$ & -4.86 to 1.34 & 0.257 \\
\hline Symptomatic & 37 & $81.5(7.0)$ & & & \\
\hline Asymptomatic & 37 & $83.3(7.2)$ & & & \\
\hline Total PFV, ml & & & $-7.2(38.6)$ & -19.7 to 5.3 & 0.250 \\
\hline Symptomatic & 39 & $183.4(27.2)$ & & & \\
\hline Asymptomatic & 39 & $190.6(29.9)$ & & & \\
\hline Caudal PFV, ml & & & $-7.2(38.2)$ & -19.97 to 5.48 & 0.256 \\
\hline Symptomatic & 37 & $152.5(25.7)$ & & & \\
\hline Asymptomatic & 37 & $159.8(31.1)$ & & & \\
\hline CSF/caudal PFV ratio & & & $0.01(0.04)$ & -0.003 to 0.022 & 0.138 \\
\hline Symptomatic & 37 & $0.071(0.032)$ & & & \\
\hline Asymptomatic & 37 & $0.061(0.030)$ & & & \\
\hline 4th ventricle/caudal PFV ratio & & & $0.0004(0.0051)$ & -0.0013 to 0.0021 & 0.649 \\
\hline Symptomatic & 37 & $0.0140(0.0045)$ & & & \\
\hline Asymptomatic & 37 & $0.0136(0.0046)$ & & & \\
\hline
\end{tabular}

$7.0 \mathrm{~mm} ; \mathrm{p}=0.026)$. The $3 \mathrm{D}$ volume comparison is also illustrated in Fig. 3, which reveals no significant difference between symptomatic and asymptomatic patients.

A secondary analysis was performed, with all patients with a syrinx included in the symptomatic group. As was the case with our primary analysis, in which groups were divided only by symptom status, no significant differences in any of the 2D or 3D metrics were observed between the symptomatic and asymptomatic groups with this secondary analysis.

\section{Discussion}

Cerebellar tonsil position is the most frequently used measurement on imaging for evaluating the presence of CM-I. Unfortunately, this measurement alone does not reliably identify the presence and severity of CM-I symp- toms across a group of patients with CM-I by the traditional radiographic criterion of a tonsil $\geq 5 \mathrm{~mm}$ below the foramen magnum. Although lower tonsil position does predict an increased likelihood of presenting with typical CM-I symptoms in general, ${ }^{37}$ many asymptomatic individuals also have low cerebellar tonsil position. ${ }^{12,15,16,20,28,41,44}$ In addition, symptoms of CM-I or syringomyelia may occur in patients with normal tonsil position in some cases., ${ }^{3,9,31,39}$

Asymptomatic or minimally symptomatic patients with CM-I incidentally discovered on imaging have become an increasingly common reason for referral to neurosurgeons. ${ }^{14,24,25,42}$ The clinical decision making is relatively clear for patients who are completely asymptomatic and for those with severe symptoms and syringomyelia that are considered clearly attributable to CM-I. However, many patients with CM-I have symptoms that may be attributed to either CM-I or other causes. ${ }^{34}$ It is important to 


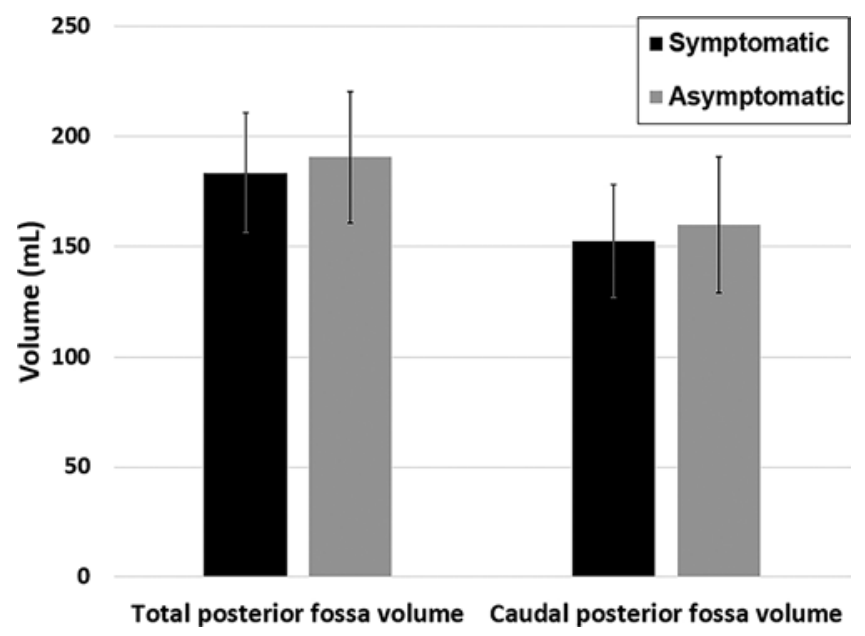

FIG. 3. Graph comparing mean total PFV (left) and caudal PFV (right) between symptomatic (black) and asymptomatic (gray) patients. Error bars equal standard deviation.

correctly diagnose asymptomatic CM-I to prevent unnecessary and ineffective surgery, as well as to avoid delayed diagnosis and treatment in truly symptomatic cases. ${ }^{4,11}$

Several morphometric studies have been published in recent years comparing radiographic posterior cranial fossa parameters between patients with CM-I and control subjects in the general population. ${ }^{5,10,13,18,26,27,32,38} \mathrm{~A}$ combination of several parameters has been suggested as an alternative diagnostic criterion to tonsil position..$^{40} \mathrm{In}$ this study, we investigated other imaging criteria that we thought could potentially distinguish symptomatic from asymptomatic CM-I. After matching for age at diagnosis, tonsil position within a 2-mm difference, tonsil morphology (rounded vs pointed), and sex, there were no clinically useful and statistically significant radiographic differences between patients with symptomatic and asymptomatic $\mathrm{CM}-\mathrm{I}$ in the anatomical measures we made.

Although the 1.1-mm difference in basilar impression between our groups was statistically significant, we do not consider the magnitude of this difference clinically useful as a means of differentiating between the groups. None of the other measures were different between the groups. Our results are at odds with a number of the studies cited above. For example, Sgouros et al., ${ }^{32}$ using segmentation techniques similar to ours, found that children with CM-I and a syrinx had a smaller PFV than both healthy children and children with CM-I without a syrinx. Patients with asymptomatic CM-I who were not surgical candidates were not included in that analysis.

We did not define our groups on the presence or absence of a syrinx; however, $42 \%$ of symptomatic patients had syringes versus only $12 \%$ of those in the asymptomatic group. Despite this, we did not detect a difference in PFV between the groups. In addition, no differences between groups were identified even in a secondary analysis that included the asymptomatic patients with syringes in the symptomatic group.

Additional diagnostic methods and criteria will be needed to accurately diagnose symptomatic CM-I to guide prognosis and management. These methods include dy- namic measurement of CSF motion using 4D flow MRI, ${ }^{8}$ longitudinal impedance to CSF flow at the foramen magnum measured using computational fluid dynamics, ${ }^{22}$ neural tissue motion quantification ${ }^{23}$ and/or volumetric displacement ${ }^{45}$ quantification over the cardiac cycle, and other techniques.

In particular, Shaffer et al. ${ }^{33}$ quantified resistance to CSF flow at the foramen magnum using computational fluid dynamics modeling in healthy subjects $(n=8)$ and in patients with symptomatic $(\mathrm{n}=10)$ and asymptomatic $(\mathrm{n}=5)$ CM-I. Impedance to CSF flow showed a trend of lower values in the asymptomatic group compared with the symptomatic group. However, the limited number of subjects did not provide adequate power for statistical relevance.

There are several important limitations to this analysis. Most importantly, the assignment of patients to groups according to symptom status is necessarily subjective. We attempted to limit the subjective nature of these decisions by only examining patients with either classic CM-I symptoms or no neurological symptoms. In future studies, symptoms may be measured more objectively by prospectively recording validated health-related quality-of-life indices, such as the Chiari Health Index for Pediatrics. ${ }^{21}$

The necessity of closely matching symptomatic and asymptomatic patients limited the number who could be included in the analysis. Our study group included pediatric CM-I patients only. A study should be conducted in adults with CM-I to confirm the findings among adult CM-I patients. In addition, the retrospective study design did not allow control of the MRI protocols used to assess each patient. Thus, many parameters varied between scans that could have affected the results, such as scan pixel size and imaging parameters that lead to different pixel intensities for fluids versus solids. Finally, all measurements were made by a single observer.

\section{Conclusions}

No significant differences were observed in 2D morphometric and 3D volumetric measurements between the asymptomatic and symptomatic pediatric CM-I groups, for which tonsil position and morphology were matched. None of the additional measurements could predict symptom status after accounting for the matched variables. Further study will be necessary to establish if any imaging test can reliably distinguish symptomatic from asymptomatic pediatric CM-I.

\section{Acknowledgments}

We thank Tom Cichonski and Holly Wagner for manuscript editing. This work was supported by The Chiari and Syringomyelia Patient Education Foundation and National Institutes of Health R-15 Grant 492 1R15NS071455-01 to Francis Loth.

\section{References}

1. Aboulezz AO, Sartor K, Geyer CA, Gado MH: Position of cerebellar tonsils in the normal population and in patients with Chiari malformation: a quantitative approach with MR imaging. J Comput Assist Tomogr 9:1033-1036, 1985

2. Aitken LA, Lindan CE, Sidney S, Gupta N, Barkovich AJ, 
Sorel M, et al: Chiari type I malformation in a pediatric population. Pediatr Neurol 40:449-454, 2009

3. Alperin N, Sivaramakrishnan A, Lichtor T: Magnetic resonance imaging-based measurements of cerebrospinal fluid and blood flow as indicators of intracranial compliance in patients with Chiari malformation. J Neurosurg 103:46-52, 2005

4. Arora P, Behari S, Banerji D, Chhabra DK, Jain VK: Factors influencing the outcome in symptomatic Chiari I malformation. Neurol India 52:470-474, 2004

5. Aydin S, Hanimoglu H, Tanriverdi T, Yentur E, Kaynar MY: Chiari type I malformations in adults: a morphometric analysis of the posterior cranial fossa. Surg Neurol 64:237-241, 2005

6. Barkovich AJ, Wippold FJ, Sherman JL, Citrin CM: Significance of cerebellar tonsillar position on MR. AJNR Am J Neuroradiol 7:795-799, 1986

7. Benglis D Jr, Covington D, Bhatia R, Bhatia S, Elhammady MS, Ragheb J, et al: Outcomes in pediatric patients with Chiari malformation Type I followed up without surgery. J Neurosurg Pediatr 7:375-379, 2011

8. Bunck AC, Kroeger JR, Juettner A, Brentrup A, Fiedler B, Crelier GR, et al: Magnetic resonance 4D flow analysis of cerebrospinal fluid dynamics in Chiari I malformation with and without syringomyelia. Eur Radiol 22:1860-1870, 2012

9. Chern JJ, Gordon AJ, Mortazavi MM, Tubbs RS, Oakes WJ: Pediatric Chiari malformation Type 0: a 12-year institutional experience. J Neurosurg Pediatr 8:1-5, 2011

10. Dagtekin A, Avci E, Kara E, Uzmansel D, Dagtekin O, Koseoglu A, et al: Posterior cranial fossa morphometry in symptomatic adult Chiari I malformation patients: comparative clinical and anatomical study. Clin Neurol Neurosurg 113:399-403, 2011

11. Dones J, De Jesús O, Colen CB, Toledo MM, Delgado M: Clinical outcomes in patients with Chiari I malformation: a review of 27 cases. Surg Neurol 60:142-148, 2003

12. Elster AD, Chen MY: Chiari I malformations: clinical and radiologic reappraisal. Radiology 183:347-353, 1992

13. Furtado SV, Reddy K, Hegde AS: Posterior fossa morphometry in symptomatic pediatric and adult Chiari I malformation. J Clin Neurosci 16:1449-1454, 2009

14. Furuya K, Sano K, Segawa H, Ide K, Yoneyama H: Symptomatic tonsillar ectopia. J Neurol Neurosurg Psychiatry 64:221-226, 1998

15. Genitori L, Peretta P, Nurisso C, Macinante L, Mussa F: Chiari type I anomalies in children and adolescents: minimally invasive management in a series of 53 cases. Childs Nerv Syst 16:707-718, 2000

16. Hofkes SK, Iskandar BJ, Turski PA, Gentry LR, McCue JB, Haughton VM: Differentiation between symptomatic Chiari I malformation and asymptomatic tonsilar ectopia by using cerebrospinal fluid flow imaging: initial estimate of imaging accuracy. Radiology 245:532-540, 2007

17. Işik N, Elmaci I, Silav G, Celik M, Kalelioğlu M: Chiari malformation type III and results of surgery: a clinical study: report of eight surgically treated cases and review of the literature. Pediatr Neurosurg 45:19-28, 2009

18. Karagöz F, Izgi N, Kapíjcíjoğlu Sencer S: Morphometric measurements of the cranium in patients with Chiari type I malformation and comparison with the normal population. Acta Neurochir (Wien) 144:165-171, 2002

19. Khalsa SSS, Siu A, DeFreitas TA, Cappuzzo JM, Myseros JS, Magge SN, et al: Comparison of posterior fossa volumes and clinical outcomes after decompression of Chiari malformation Type I. J Neurosurg Pediatr 19:511-517, 2017

20. Krueger KD, Haughton VM, Hetzel S: Peak CSF velocities in patients with symptomatic and asymptomatic Chiari I malformation. AJNR Am J Neuroradiol 31:1837-1841, 2010

21. Ladner TR, Westrick AC, Wellons JC III, Shannon CN:
Health-related quality of life in pediatric Chiari Type I malformation: the Chiari Health Index for Pediatrics. J Neurosurg Pediatr 17:76-85, 2016

22. Martin BA, Kalata W, Shaffer N, Fischer P, Luciano M, Loth $\mathrm{F}$ : Hydrodynamic and longitudinal impedance analysis of cerebrospinal fluid dynamics at the craniovertebral junction in type I Chiari malformation. PLoS One 8:e75335, 2013

23. Martin BA, Shaffer N, Lowenkamp M, Loth F, Tew J, Luciano M: Clinical importance of neural tissue deformation in type I Chiari malformation. J Neurosurg Pediatr 13:A348, 2014 (Abstract)

24. Meadows J, Kraut M, Guarnieri M, Haroun RI, Carson BS: Asymptomatic Chiari Type I malformations identified on magnetic resonance imaging. J Neurosurg 92:920-926, 2000

25. Morris Z, Whiteley WN, Longstreth WT Jr, Weber F, Lee YC, Tsushima Y, et al: Incidental findings on brain magnetic resonance imaging: systematic review and meta-analysis. BMJ 339:b3016, 2009

26. Nishikawa M, Sakamoto H, Hakuba A, Nakanishi N, Inoue Y: Pathogenesis of Chiari malformation: a morphometric study of the posterior cranial fossa. J Neurosurg 86:40-47, 1997

27. Noudel R, Jovenin N, Eap C, Scherpereel B, Pierot L, Rousseaux P: Incidence of basioccipital hypoplasia in Chiari malformation type I: comparative morphometric study of the posterior cranial fossa. Clinical article. J Neurosurg 111:1046-1052, 2009

28. Novegno F, Caldarelli M, Massa A, Chieffo D, Massimi L, Pettorini B, et al: The natural history of the Chiari Type I anomaly. J Neurosurg Pediatr 2:179-187, 2008

29. Pomeraniec IJ, Ksendzovsky A, Awad AJ, Fezeu F, Jane JA Jr: Natural and surgical history of Chiari malformation Type $\mathrm{I}$ in the pediatric population. J Neurosurg Pediatr 17:343352,2016

30. Schneider CA, Rasband WS, Eliceiri KW: NIH Image to Image J: 25 years of image analysis. Nat Methods 9:671-675, 2012

31. Sekula RF Jr, Jannetta PJ, Casey KF, Marchan EM, Sekula LK, McCrady CS: Dimensions of the posterior fossa in patients symptomatic for Chiari I malformation but without cerebellar tonsillar descent. Cerebrospinal Fluid Res 2:11, 2005

32. Sgouros S, Kountouri M, Natarajan K: Posterior fossa volume in children with Chiari malformation Type I. J Neurosurg 105 (2 Suppl):101-106, 2006

33. Shaffer N, Martin BA, Rocque B, Madura C, Wieben O, Iskandar BJ, et al: Cerebrospinal fluid flow impedance is elevated in Type I Chiari malformation. J Biomech Eng 136:021012, 2014

34. Shehu B, Ismail N, Mahmud M, Hassan I: Chiari I malformation: a missed diagnosis. Ann Afr Med 5:206-208, 2006

35. Smith BW, Strahle J, Bapuraj JR, Muraszko KM, Garton HJ, Maher CO: Distribution of cerebellar tonsil position: implications for understanding Chiari malformation. J Neurosurg 119:812-819, 2013

36. Strahle J, Muraszko KM, Garton HJ, Smith BW, Starr J, Kapurch JR II, et al: Syrinx location and size according to etiology: identification of Chiari-associated syrinx. J Neurosurg Pediatr 16:21-29, 2015

37. Strahle J, Muraszko KM, Kapurch J, Bapuraj JR, Garton HJ, Maher CO: Chiari malformation Type I and syrinx in children undergoing magnetic resonance imaging. J Neurosurg Pediatr 8:205-213, 2011

38. Trigylidas T, Baronia B, Vassilyadi M, Ventureyra EC: Posterior fossa dimension and volume estimates in pediatric patients with Chiari I malformations. Childs Nerv Syst 24:329-336, 2008

39. Tubbs RS, Elton S, Grabb P, Dockery SE, Bartolucci AA, 
Oakes WJ: Analysis of the posterior fossa in children with the Chiari 0 malformation. Neurosurgery 48:1050-1055, 2001

40. Urbizu A, Poca MA, Vidal X, Rovira A, Sahuquillo J, Macaya A: MRI-based morphometric analysis of posterior cranial fossa in the diagnosis of Chiari malformation type I. J Neuroimaging 24:250-256, 2014

41. Ventureyra EC, Aziz HA, Vassilyadi M: The role of cine flow MRI in children with Chiari I malformation. Childs Nerv Syst 19:109-113, 2003

42. Vernooij MW, Ikram MA, Tanghe HL, Vincent AJ, Hofman A, Krestin GP, et al: Incidental findings on brain MRI in the general population. N Engl J Med 357:1821-1828, 2007

43. Whitson WJ, Lane JR, Bauer DF, Durham SR: A prospective natural history study of nonoperatively managed Chiari I malformation: does follow-up MRI surveillance alter surgical decision making? J Neurosurg Pediatr 16:159-166, 2015

44. Wu YW, Chin CT, Chan KM, Barkovich AJ, Ferriero DM: Pediatric Chiari I malformations: do clinical and radiologic features correlate? Neurology 53:1271-1276, 1999

45. Yiallourou TI, Kröger JR, Stergiopulos N, Maintz D, Martin BA, Bunck AC: Comparison of 4D phase-contrast MRI flow measurements to computational fluid dynamics simulations of cerebrospinal fluid motion in the cervical spine. PLoS One 7:e52284, 2012

\section{Disclosures}

The authors report no conflict of interest concerning the materials or methods used in this study or the findings specified in this paper.

\section{Author Contributions}

Conception and design: Maher, Martin, Strahle, Loth. Acquisition of data: Maher, Khalsa, Geh, Strahle. Analysis and interpretation of data: all authors. Drafting the article: Maher, Khalsa, Geh. Critically revising the article: all authors. Reviewed submitted version of manuscript: all authors. Statistical analysis: Khalsa. Study supervision: Maher.

\section{Correspondence}

Cormac O. Maher, Department of Neurosurgery, University of Michigan, 1500 East Medical Center Dr., Rm. 3552 TC, Ann Arbor, MI 48109-5338. email: cmaher@med.umich.edu. 